\title{
Effect of Diffuse Panbronchiolitis Critical Region 1 Polymorphisms on the Risk of Aspirin-Exacerbated Respiratory Disease in Korean Asthmatics
}

\author{
Jin Sol Lee, Joon Seol Bae PhD, Jeong-Hyun Kim PhD, Jason Yongha Kim MSc, Tae Joon Park, \\ Charisse Flerida A Pasaje MSc, Byung-Lae Park PhD, Hyun Sub Cheong PhD, Soo-Taek Uh MD, \\ Jong-Sook Park MD, Choon-Sik Park MD, and Hyoung Doo Shin PhD
}

\begin{abstract}
BACKGROUND: The functional role of the human diffuse panbronchiolitis critical region 1 (DPCR1) gene, located in the major histocompatibility complex class I, has not been widely investigated. However, this gene is a well known genetic marker for diffuse panbronchiolitis, a disease affecting human respiratory bronchioles. In this study we explored the association between polymorphisms in DPCR1 and aspirin-exacerbated respiratory disease (AERD), an asthma phenotype. METHODS: Genotyping of 6 polymorphisms was carried out in a total of 189 Korean asthmatic patients stratified into 93 AERD cases and 96 aspirin tolerant asthma controls. Subjects who exhibited significant decrease of $\mathrm{FEV}_{1}$ by aspirin provocation were identified as AERD subjects. Logistic and regression analyses were performed to investigate the association between DPCR1 polymorphisms and the risk of AERD as well as $\mathrm{FEV}_{1}$ decline. RESULTS: Initial analysis revealed significant association of $r$ s2517449 with AERD, with a $P$ value of .03 via a recessive model; however, the association signal disappeared after multiple testing corrections. In addition, $r$ s 2517449 and $r$ r2240804 also showed association signals with decline of $\mathrm{FEV}_{1}$ after aspirin provocation $(P=.007$ and .03 , respectively, in a recessive model). After testing for multiple comparisons, only the association signal from $r$ s2517449 was retained $\left(P^{\text {corr }}=.04\right)$, while other polymorphisms showed no associations with the risk of AERD and $\mathrm{FEV}_{1}$ decline. CONCLUSIONS: Our results show that polymorphisms in DPCR1 are not associated with the risk of AERD. Key words: aspirin-exacerbated respiratory disease; aspirin-tolerant asthma; DPCR1; FEV ${ }_{1}$; haplotype; single nucleotide polymorphism. [Respir Care 2012;57(5):758-763. (C) 2012 Daedalus Enterprises]
\end{abstract}

\section{Jin Sol Lee and Joon Seol Bae PhD are co-first authors.}

Jin Sol Lee, Joon Seol Bae PhD, Jeong-Hyun Kim PhD, Jason Yongha Kim MSc, Tae Joon Park, Charisse Flerida A Pasaje MSc, and Hyoung Doo Shin PhD are affiliated with the Department of Life Science, Sogang University, Seoul, Republic of Korea. Byung-Lae Park PhD, Hyun Sub Cheong $\mathrm{PhD}$, and Hyoung Doo Shin PhD are affiliated with the Department of Genetic Epidemiology, SNP Genetics, Seoul, Republic of Korea. Soo-Taek Uh MD and Choon-Sik Park MD are affiliated with the Division of Allergy and Respiratory Medicine, Soonchunhyang University Seoul Hospital, Seoul, Republic of Korea. Jong-Sook Park MD is affiliated with the Genome Research Center for Allergy and Respiratory Disease, Soonchunhyang University Bucheon Hospital, Bucheon, Republic of Korea.

This work was supported by grant 2009-0080157 from the National Research Foundation of Korea, Republic of Korea, and by grant A010249 from the Korea Healthcare Technology Research and Development Project, Ministry for Health, Welfare, and Family Affairs, Republic of Korea. The DNA samples were generously provided by Soonchunhyang University, Bucheon Hospital Biobank, a member of the National Biobank of Korea, supported by the Ministry of Health, Welfare, and Family Affairs, Republic of Korea.

The authors have disclosed no conflicts of interest.

Correspondence: Hyoung Doo Shin PhD, Department of Life Science, Sogang University, Seoul 121-742, Republic of Korea.E-mail: hdshin@sogang.ac.kr; and Choon-Sik Park MD, Division of Allergy and Respiratory Medicine, Soonchunhyang University Seoul Hospital, Seoul 140-743, Republic of Korea. E-mail: scalr@schbc.ac.kr.

DOI: $10.4187 /$ respcare. 01480 


\section{Introduction}

Aspirin-exacerbated respiratory disease (AERD) was first described by Widal et al in 1992, who mentioned that the symptoms of the disease included asthma and nasal polyposis, which is caused by hypersensitivity to nonsteroidal anti-inflammatory drugs such as aspirin. ${ }^{1} \mathrm{Al}-$ though aspirin is a widely used medication for relieving pain, side effects associated with aspirin intake have been reported in $20 \%$ of asthmatics. ${ }^{2}$ Although AERD pathogenesis has not yet been fully understood, abnormal production of leukotrienes through the arachidonic acid cascade associated with human inflammation response has been regarded as the main cause of the disease. ${ }^{3}$ Blocking of prostaglandin production by non-steroidal anti-inflammatory drugs has also been implicated in inflammatory responses associated with the immune system.

The diffuse panbronchiolitis critical region 1 (DPCR1) gene, located between HLA-B and HLA-A on chromosome 6p21.33, is classified as one of the human major histocompatibility complex (MHC) class I molecules. A previous study has reported that approximately $200 \mathrm{~kb}$ of the MHC class I region, which contains the DPCR1 gene, may contain markers for diagnosis of diffuse panbronchiolitis, a bronchiolar disease that affects human airways. ${ }^{1}$ However, to our knowledge, the association between DPCR1 variations and risk of AERD has not yet been investigated.

To date, some groups have reported the function of DPCR1 in human diseases. One recent study that screened candidate genes of HIV-1 control revealed that singlenucleotide polymorphisms (SNPs) in DPCR1 ranked among the top 500 polymorphisms with the highest effect, ${ }^{2}$ suggesting that although the function of DPCR1 still remains unknown, it might play a role in human immune diseases. In addition, another study has reported that some SNPs used in this study showed significant association signals with systemic lupus erythematosus. ${ }^{3}$ A more recent finding has revealed that 2 DPCR1 adjacent genes, mucin-like genes (PBMUCL1,2), are associated with diffuse panbronchiolitis and affect airway epithelial cell redifferentiation. ${ }^{4}$ Furthermore, a study by Kim et al has revealed recently that aspirin can inhibit the MHC class I restricted exogenous antigen presenting capability of dendritic cells, which have an important role in the immune system. ${ }^{5}$ These results seemed to implicate the important role of DPCR1, which is located in the MHC I region in the human immune system.

In the present study we hypothesized that DPCR1 might be a candidate gene for other human airway diseases, such as AERD, and carried out an association analysis in a Korean asthma cohort.

\section{QUICK LOOK}

\section{Current knowledge}

The diffuse panbronchiolitis critical region 1 (DPCR1) gene is a well know genetic marker for diffuse panbronchiolitis. The relationship to DPCR1 polymorphisms in aspirin-exacerbated respiratory disease is unknown.

\section{What this paper contributes to our knowledge}

DPCR1 polymorphisms are not associated with the risk of aspirin-exacerbated respiratory disease.

\section{Methods}

\section{Study Subjects}

All of the asthmatics, including 93 AERD asthmatics and 96 aspirin-tolerant asthma subjects, were recruited from consecutive out-patients of Soonchunhyang, Chonnam, Chungbuk, Seoul National, and Chung-Ang University hospitals, comprising the Asthma Genome Research Center in Korea. All of the subjects showed clinical symptoms that met the criteria for asthma according to the Global Initiative for Asthma. ${ }^{6}$ Evaluation included dyspnea and wheezing during the past year, plus one of: airway reversibility measured by a positive bronchodilator response of $>15 \%$ increase in $\mathrm{FEV}_{1}$ or $>12 \%$ increase in $\mathrm{FEV}_{1}$ plus $200 \mathrm{~mL}$ following inhalation of a short-acting bronchodilator; airway hyper-reactivity to $<10 \mathrm{mg} / \mathrm{mL}$ provocational concentration of methacholine that produced a $20 \%$ decrease in $\mathrm{FEV}_{1}$; or $>20 \%$ increase in $\mathrm{FEV}_{1}$ following 2 weeks of treatment with inhaled steroids and long-acting bronchodilators. ${ }^{7}$ Twenty-four common inhalant allergens (eg, dust mites, cat fur, dog fur, cockroaches, grasses, trees, ragweed pollen) were used in a skin-prick test (Bencard, Brentford, United Kingdom). Total immunoglobulin E was measured using the CAP system (Pharmacia Diagnostics, Uppsala, Sweden). Atopy was defined as a wheal reaction equal to or greater than histamine, or $3 \mathrm{~mm}$ in diameter. Pulmonary function tests were performed using a spirometry system (Vmax Series 2130 Autobox, SensorMedics, Yorba Linda, California) with adherence to the American Thoracic Society guidelines. ${ }^{8}$ The reference values of lung functions used were according to the standards of Morris. ${ }^{9}$ All asthmatics underwent oral aspirin challenge that was performed with increasing doses of aspirin (10$450 \mathrm{mg}),{ }^{10,11}$ with modifications. The subjects reported no increase in asthma symptoms or respiratory-tract infections within 6 weeks prior to the test. Briefly, subjects with 


\section{Diffuse Panbronchiolitis Critical Region 1 Polymorphisms and Aspirin-Exacerbated Asthma}

history of aspirin hypersensitivity were given $30 \mathrm{mg}$, and those having no history of aspirin hypersensitivity started with $100 \mathrm{mg}$ of aspirin orally. Symptoms, external signs (urticaria, angioedema, rhinorrhea), and $\mathrm{FEV}_{1}$ were documented every $30 \mathrm{~min}$ for a period of 2 hours. In the absence of any symptoms or signs suggestive of adverse reaction after 2 hours, $60 \mathrm{mg}$ or $100 \mathrm{mg}$ of aspirin were administered and the same measurements were repeated every 1 hour, with doses of $450 \mathrm{mg}$ until the subject developed a reaction. If no reaction occurred 5 hours after the final dose, the test was deemed negative. Changes in the $\mathrm{FEV}_{1}$ were followed for 5 hours after the final aspirin dose. Aspirin-induced bronchospasm, reflected by the rate $(\%)$ of decline in $\mathrm{FEV}_{1}$, was calculated as the prechallenge $\mathrm{FEV}_{1}$ minus the post-challenge $\mathrm{FEV}_{1}$ divided by the pre-challenge $\mathrm{FEV}_{1}$. Categorization of subjects was based on individual oral aspirin challenge reactions. Asthmatics exhibiting $\geq 20 \%$ decrease in $\mathrm{FEV}_{1}$ or a $15-19 \%$ decrease in $\mathrm{FEV}_{1}$ with naso-ocular or cutaneous reactions were diagnosed as AERD cases, whereas those demonstrating $<15 \%$ decrease in $\mathrm{FEV}_{1}$ without naso-ocular or cutaneous reactions were identified as aspirin-tolerant asthma controls. A diagnosis of nasal polyps was made based on the presence of endoscopically visible nasal polyps arising from the middle nasal meatus. All subjects provided written informed consent, and the study protocols were approved by the institutional review board of each hospital.

\section{SNP Selection and Genotyping}

We selected candidate polymorphic SNPs in the National Center for Biotechnology Information and the International HapMap Project (http://hapmap.ncbi.nlm.nih. gov/) databases, based on the frequencies in Asian population and linkage disequilibrium (LD) status. For examination of AERD risk association, we genotyped 6 SNPs in the DPCR1 gene. Genotyping was carried out with $20 \mathrm{ng}$ of genomic DNA, using TaqMan assay in sequence detection system software (ABI prism 7900HT, version 2.3, Applied Biosystems, Carlsbad, California) in 93 AERD cases and 96 aspirin-tolerant asthma controls, with the assessment of data quality by duplicate DNAs $(n=10)$.

\section{Statistics}

We calculated LD in all pairs of biallelic loci, using Lewontin's $\mathrm{D}^{\prime}\left(\mathrm{D}^{\prime}\right)^{12}$ and $\mathrm{r}^{2}$. The PHASE algorithm (version 2.0), developed by Stephens et al, was used for inferring haplotypes. ${ }^{13}$ Associations of genotypes and haplotypes in the DPCR1 gene with AERD were calculated using logistic analysis adjusted for age, sex, smoking status, atopy, and body mass index as covariates. We also
Table 1. Clinical Information of Study for Polymorphisms in DPCR 1

\begin{tabular}{|c|c|c|}
\hline & $\begin{array}{c}\text { Aspirin- } \\
\text { Exacerbated } \\
\text { Respiratory } \\
\text { Disease } \\
(n=93)\end{array}$ & $\begin{array}{l}\text { Aspirin- } \\
\text { Tolerant } \\
\text { Asthma } \\
(n=96)\end{array}$ \\
\hline Age, mean (range) y & $44.4(17-73)$ & $45.8(15-77)$ \\
\hline Onset age, mean (range) $\mathrm{y}^{*}$ & $38.0(0-70)$ & $38.0(5-73)$ \\
\hline Body mass index, $\mathrm{kg} / \mathrm{m}^{2}$ & $23.5 \pm 3.2$ & $24.4 \pm 3.3$ \\
\hline Blood eosinophil, \% & $6.3 \pm 5.8$ & $4.9 \pm 4.2$ \\
\hline FVC, $\%$ predicted & $89.9 \pm 14.7$ & $87.8 \pm 12.8$ \\
\hline $\mathrm{FEV}_{1}, \%$ predicted & $86.6 \pm 16.7$ & $88.3 \pm 17.0$ \\
\hline $\mathrm{PC}_{20}$ methacholine, $\mathrm{mg} / \mathrm{mL}$ & $4.2 \pm 7.2$ & $3.0 \pm 4.3$ \\
\hline Total immunoglobulin E, IU/mL & $321.7 \pm 623.3$ & $309.5 \pm 426.0$ \\
\hline Decline after aspirin challenge, $\% \dagger$ & $23.6 \pm 14.5$ & $0.9 \pm 2.8$ \\
\hline Sex, no. male/female & $32 / 61$ & $24 / 72$ \\
\hline Ex-smoker/current smoker, $\%$ & $15.6 / 9.4$ & $6.5 / 12.9$ \\
\hline Positive rate of skin test, $\%$ & 61.5 & 57.0 \\
\hline $\begin{array}{l}\text { Positive rate of aspirin side effect, } \\
\% \dagger\end{array}$ & 26.7 & 8.4 \\
\hline Positive rate of polyposis, $\% \dagger$ & 63.9 & 29.3 \\
\hline $\begin{array}{l} \pm \text { values are mean } \pm \mathrm{SD} \\
* \text { Age indicates a first medical examination. } \\
\dagger P<.001 \text {, compared to aspirin-tolerant asthma } \\
\mathrm{DPCR} 1=\text { diffuse panbronchiolitis critical region } \\
\mathrm{PC}_{20}=\text { provocational concentration that produce }\end{array}$ & $\begin{array}{l}\text { ontrols. } \\
1 \text { gene } \\
\text { a } 20 \% \text { decrease in }\end{array}$ & \\
\hline
\end{tabular}

performed linear regression analysis to determine the differences in the rates of decline in $\mathrm{FEV}_{1}$ following aspirin challenge among the genotypes and haplotypes. Data were adjusted, managed, and analyzed using software (SAS version 9.1, SAS Institute, Cary, North Carolina). Statistical significance was set as $<.05$. Furthermore, the effective number of independent marker loci (Meff) was calculated for multiple testing corrections using SNPSpD (http:// genepi.qimr.edu.au/general/daleN/SNPSpD/), a program that is based on the spectral decomposition $(\mathrm{SpD})$ of matrices of pair-wise LD between SNPs.

\section{Results}

From analysis of the subjects' characteristics, we observed that AERD patients show significantly greater $F E V_{1}$ decline after aspirin challenge, compared to the aspirintolerant asthma group $(23.6 \pm 14.5 \%$ vs $0.9 \pm 2.8 \%$, respectively, $P<.001$, Table 1 ). The case group also shows a higher percentage of positive rate of side effect measured through external signs (urticaria, angioedema, rhinorrhea) after aspirin treatment $(26.7 \%$ vs $8.4 \%$, $P<.001$, see Table 1$)$ and polyposis rate $(63.9 \%$ vs $29.3 \%, P<.001$, see Table 1). Other diagnosis factors showed no significant association between the AERD and 


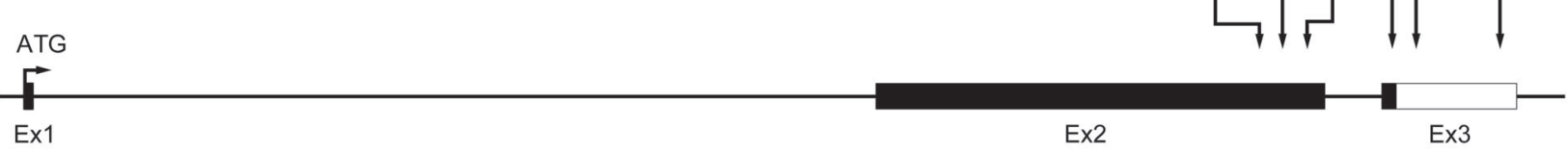

B

\begin{tabular}{|c|c|c|c|c|c|c|}
\hline $\begin{array}{c}\text { Haplo- } \\
\text { type }\end{array}$ & 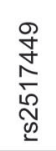 & 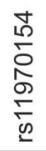 & 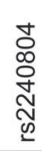 & 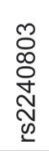 & 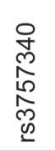 & Frequency \\
\hline ht1 & A & G & C & $\mathrm{T}$ & $c$ & 0.364 \\
\hline ht2 & G & G & T & C & $\mathrm{T}$ & 0.235 \\
\hline ht3 & A & G & C & C & $\mathrm{T}$ & 0.230 \\
\hline ht4 & A & $c$ & c & C & $c$ & 0.104 \\
\hline ht5 & G & G & c & C & $\mathrm{T}$ & 0.067 \\
\hline
\end{tabular}

C
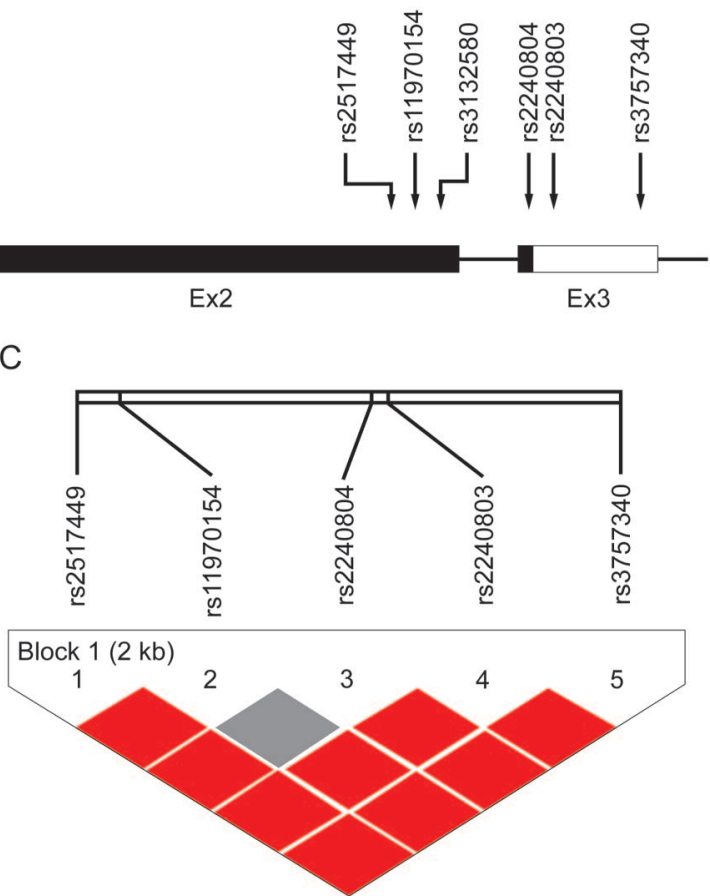

Fig. 1. Schematic physical map, haplotypes, and linkage disequilibrium (LD) plot of diffuse panbronchiolitis critical region 1 (DPCR1). A: Polymorphisms identified in DPCR1. Coding exons are marked by shaded blocks and 3'-untranslated region by white blocks. The LD coefficients $\left(r^{2}\right)$ are based on the genotypes of Korean samples. B: Haplotypes of DPCR 1 in the Korean population. Only those with frequencies over 0.05 are shown. C: LD coefficients $\left(\mathrm{D}^{\prime}\right.$ and $\left.\mathrm{r}^{2}\right)$ among the selected single-nucleotide polymorphisms (SNPs) based on the genotypes of whole study subjects in this study $(n=189)$.

aspirin-tolerant asthma groups. The clinical profiles and analysis results are summarized in Table 1.

For the logistic and regression analysis we genotyped all subjects for 6 common polymorphisms ( $r s 2517449$, rs11970154, rs3132580, rs2240804, rs2240803, and rs3757340). Calculation of LD plot was performed with the exception of $r s 3132580$, since its frequency was lower than 0.05. The genetic map of DPCR1 is shown in Figure 1, and minor allele frequencies for each polymorphism in the AERD and aspirin-tolerant asthma groups are displayed in Table 2. We also calculated for deviations from Hardy-Weinberg equilibrium, and all polymorphisms were found to be in Hardy-Weinberg equilibrium except for $r s 2517449$ in the AERD subjects. Four variants ( $r s 2517449, r s 11970154, r s 3132580$, and $r s 2240804$ ) were located in the translational region of the gene, while the other 2 SNPs (rs2240803 and rs3757340) were located in the $5^{\prime}$-untranslated region (see Fig. 1A). Three sites of amino acid substitutions, from glycine to arginine in rs11970154, glutamine to lysine in rs3132580, and arginine to glutamic acid in $r s 2240804$ were observed. This information is summarized in Table 2.

From the initial logistic analysis we revealed that the $r s 2517449$ variant is significantly associated with the risk of AERD in the recessive model $(P=.03$, with odds ratio of 0.27 , and $95 \% \mathrm{CI}=0.08-0.90$, Table 3 ). The $r s 3132580$
Table 2. Information on Study Alleles in DPCR1

\begin{tabular}{|c|c|c|c|c|c|}
\hline \multirow[t]{2}{*}{ Loci } & \multirow{2}{*}{$\begin{array}{l}\text { Amino } \\
\text { Acid } \\
\text { Change }\end{array}$} & \multicolumn{2}{|c|}{$\begin{array}{l}\text { Minor Allele } \\
\text { Frequency }\end{array}$} & \multicolumn{2}{|c|}{$\begin{array}{c}\text { Hardy-Weinberg } \\
\text { Equilibrium }\end{array}$} \\
\hline & & AERD & ATA & AERD & ATA \\
\hline rs 2517449 & NA & 0.30 & 0.31 & 0.04 & 0.16 \\
\hline rs11970154 & Gly55Arg & 0.12 & 0.09 & 0.83 & 0.85 \\
\hline rs3132580 & Glu137Lys & 0.04 & 0.03 & 0.70 & 0.75 \\
\hline$r s 2240804$ & Arg235Gln & 0.23 & 0.24 & 0.12 & 0.21 \\
\hline$r s 2240803$ & NA & 0.38 & 0.35 & 0.63 & 0.89 \\
\hline rs3757340 & NA & 0.49 & 0.44 & 0.34 & 0.45 \\
\hline $\begin{array}{l}\text { DPCR1 = diffuse } \\
\text { AERD = aspirin- } \\
\text { ATA = aspirin-to } \\
\text { NA = not applica }\end{array}$ & $\begin{array}{l}\text { nbronchiolitis cri } \\
\text { cerbated respirat } \\
\text { ant asthma }\end{array}$ & $\begin{array}{l}\text { region } 1 \mathrm{~g} \\
\text { lisease }\end{array}$ & & & \\
\hline
\end{tabular}

variant was not analyzed in the recessive model because there was no existing sample with 2 recessive alleles of the polymorphism. For adequate comparisons between polymorphisms, we performed multiple testing corrections with Meff $=5.0676$. The association signal initially detected failed to reach significance after corrections (see Table 3). Furthermore, rs 2517449 and $r s 2240804$ were also found to be associated with a fall in the rate of $\mathrm{FEV}_{1}$ via a recessive mechanism $(P=.007-.03$, Table 4$)$. The num- 


\section{Diffuse Panbronchiolitis Critical Region 1 Polymorphisms and Aspirin-Exacerbated Asthma}

Table 3. Associations of DPCR1 Polymorphisms and Haplotypes With Risk of Aspirin-Exacerbated Respiratory Disease

\begin{tabular}{|c|c|c|c|c|c|c|c|c|c|}
\hline \multirow{2}{*}{ Loci } & \multicolumn{3}{|c|}{ Co-dominant } & \multicolumn{3}{|c|}{ Dominant } & \multicolumn{3}{|c|}{ Recessive } \\
\hline & OR $(95 \% \mathrm{CI})$ & $P$ & $P^{c o r r}$ & OR $(95 \% \mathrm{CI})$ & $P$ & $P^{c o r r}$ & OR $(95 \% \mathrm{CI})$ & $P$ & $P^{c o r r}$ \\
\hline$r s 2517449$ & $0.89(0.56-1.40)$ & .60 & .99 & $1.19(0.66-2.13)$ & .56 & .99 & $0.27(0.08-0.90)$ & .03 & .16 \\
\hline rs11970154 & $1.24(0.62-2.46)$ & .54 & .99 & $1.29(0.61-2.69)$ & .51 & .99 & $0.97(0.05-17.55)$ & .98 & .99 \\
\hline$r s 3132580$ & $1.22(0.38-3.87)$ & .74 & .99 & $1.22(0.38-3.87)$ & .74 & .99 & ND & NA & NA \\
\hline$r s 2240804$ & $0.85(0.52-1.39)$ & .52 & .99 & $1.06(0.59-1.91)$ & .85 & .99 & $0.20(0.04-1.00)$ & .05 & .25 \\
\hline$r s 2240803$ & $1.23(0.79-1.91)$ & .36 & .99 & $1.37(0.75-2.50)$ & .31 & .99 & $1.17(0.49-2.81)$ & .72 & .99 \\
\hline rs3757340 & $1.34(0.86-2.07)$ & .20 & .99 & $1.51(0.77-2.97)$ & .24 & .99 & $1.39(0.67-2.90)$ & .38 & .99 \\
\hline DPCR1_ht $3 c$ & $0.77(0.46-1.29)$ & .32 & .99 & $0.81(0.45-1.47)$ & .49 & .99 & $0.38(0.07-1.97)$ & .25 & .99 \\
\hline DPCR1_ht5c & $1.10(0.46-2.59)$ & .84 & .99 & $1.10(0.46-2.59)$ & .84 & .99 & ND & NA & NA \\
\hline \multicolumn{10}{|c|}{$\begin{array}{l}\text { SNP }=\text { single-nucleotide polymorphism } \\
\text { DPCR } 1=\text { diffuse panbronchiolitis critical region } 1 \text { gene } \\
P^{\text {corr }}=\text { corrected } P \text { using multiple testing corrections } \\
\text { OR }=\text { odds ratio } \\
\text { ND }=\text { no data collected } \\
\text { NA }=\text { not applicable }\end{array}$} \\
\hline
\end{tabular}

Table 4. Comparison Between Genotype Frequencies of SNPs and Haplotypes in DPCR1 and FEV ${ }_{1}$ Decline After Aspirin Challenge

\begin{tabular}{|c|c|c|c|c|c|c|c|c|c|}
\hline \multirow{2}{*}{ Loci } & \multirow{2}{*}{$\begin{array}{l}\text { Common Allele/ } \\
\text { Common Allele }\end{array}$} & \multirow{2}{*}{$\begin{array}{l}\text { Common Allele/ } \\
\text { Rare Allele }\end{array}$} & \multirow{2}{*}{$\begin{array}{l}\text { Rare Allele/ } \\
\text { Rare Allele }\end{array}$} & \multicolumn{2}{|c|}{ Co-dominant } & \multicolumn{2}{|c|}{ Dominant } & \multicolumn{2}{|c|}{ Recessive } \\
\hline & & & & $P$ & $\overline{P^{\text {corr }}}$ & $P$ & $P^{\text {corr }}$ & $P$ & $P^{\text {corr }}$ \\
\hline$r s 2517449$ & $91(11.68 \pm 14.89)$ & $82(14.34 \pm 16.26)$ & $16(2.91 \pm 8.75)$ & .29 & .99 & .90 & .99 & .007 & .04 \\
\hline rs11970154 & $150(11.05 \pm 14.77)$ & $35(16.27 \pm 17.81)$ & $2(10.00 \pm 9.90)$ & .17 & .84 & .11 & .57 & .72 & .99 \\
\hline$r s 3132580$ & $174(11.88 \pm 15.46)$ & $13(13.73 \pm 15.29)$ & ND & .66 & .99 & .66 & .99 & NA & NA \\
\hline$r s 2240804$ & $109(11.99 \pm 15.33)$ & $68(13.44 \pm 16.00)$ & $10(2.62 \pm 8.33)$ & .35 & .99 & .90 & .99 & .03 & .10 \\
\hline$r s 2240803$ & $75(11.38 \pm 15.23)$ & $88(12.60 \pm 15.71)$ & $24(11.86 \pm 15.45)$ & .57 & .99 & .51 & .99 & .85 & ND \\
\hline$r s 3757340$ & $49(8.96 \pm 13.25)$ & $101(13.14 \pm 16.24)$ & $37(12.97 \pm 15.61)$ & .15 & .74 & .08 & .42 & .58 & ND \\
\hline DPCR $1 \_h t 3 c$ & $109(12.53 \pm 16.24)$ & $69(11.42 \pm 14.25)$ & $8(9.63 \pm 16.06)$ & .62 & .99 & .64 & .99 & .79 & .99 \\
\hline DPCR1_ht5c & $161(12.11 \pm 15.36)$ & $25(11.28 \pm 16.34)$ & ND & .71 & .99 & .71 & .99 & NA & NA \\
\hline \multicolumn{10}{|c|}{$\begin{array}{l}\text { SNP }=\text { single-nucleotide polymorphism } \\
\text { DPCR } 1=\text { diffuse panbronchiolitis critical region } 1 \text { gene } \\
P^{\text {corr }}=\text { corrected } P \text { using multiple testing corrections } \\
\text { NA = not applicable }\end{array}$} \\
\hline
\end{tabular}

ber of genotypes is displayed along with the results of regression analysis in Table 3. However, only the signal from $r s 2517449$ was retained after corrections $\left(P^{c o r r}=.04\right.$, Table 4).

\section{Discussion}

Although the mechanisms of diffuse panbronchiolitis still remain poorly understood, symptoms of diffuse panbronchiolitis partially overlap with other respiratory diseases, like chronic bronchitis and asthma. ${ }^{14,15}$ In addition, C6orf37OS, another name for DPCR1, is highly expressed in the lungs, suggesting that it may be a potential diffuse panbronchiolitis susceptible gene located in the HLA region. ${ }^{1}$ Genes in the HLA region have been known to play important roles in regulating the antigen presenting system of the adaptive immune system, supported by reports showing that airway inflammation in aspirin hypersensitive patients is due to eosinophil infiltration. ${ }^{16}$ Given the observed increase in the number of dendritic cells that play important roles in antigen presenting and recruitment of other inflammation associated cells in bronchiolar tissues, variations of MHC, including DPCR1, are expected to be involved in AERD pathogenesis in this study. ${ }^{17}$

Among the SNPs in DPCR1, we selected common polymorphisms with frequencies higher than 0.05 , and therefore a total of 6 variants were analyzed in this study. From the variants screened in the systemic lupus erythematosus study, 3 SNPs (rs31325870, rs2240803, and rs3757340) were also included in this study and may have meaningful $P$ values, with lower than $.05 .^{3}$ However, results from logistic analysis in this study showed no association be- 


\section{Diffuse Panbronchiolitis Critical Region 1 Polymorphisms and Aspirin-Exacerbated Asthma}

tween the risk of AERD and 3 SNPs that were also included in the systemic lupus erythematosus study. The marginal association signal detected in $r s 2517449$ with a $P$ value of .03 with an odds ratio of 0.27 (95\% CI $=0.08-$ 0.90) disappeared after multiple testing corrections. In addition, we were able to detect amino acid changes in 3 polymorphisms, rs11970154 with glycine to arginine, rs3132580 with glutamine to lysine, and rs2240804 with arginine to glutamic acid, but these SNPs were not associated with risk of AERD. Other SNPs also show no association with the risk of AERD. Analysis of 5 major haplotypes having frequencies over 0.05 were revealed to have the same effect as the analyzed SNPs (rs2240803 with $h t 1, r s 2240804$ with $h t 2$, and rs11970154 with $h t 4$ ), and therefore the results were not shown in Table 3. DPCR1 haplotypes were also found to have no associations with the risk of AERD.

In the regression analysis that focused on $\mathrm{FEV}_{1}$ decline after aspirin challenge, 2 polymorphisms, rs 2517449 and $r s 2240804$, showed significant associations, with $P$ values of .007 and .03 in a recessive model. Furthermore, the association signal of $r s 2517449$ remained robust after multiple testing corrections $\left(P^{\text {corr }}=.04\right)$. This result indicates that $r s 2517449$ may affect the fall rate of $\mathrm{FEV}_{1}$. Relating this finding to the results of logistic analysis, this significant signal might affect the association signal in initial analysis. In this case, one possible role of SNPs in exon is modifying the gene splicing related sequence for enhanced and more accurate splicing. Indeed, the rs2517449 was located in the exonic splicing enhancer or exonic splicing silencer, as mentioned in the National Institutes of Health database. To date, researchers have demonstrated that the exonic splicing enhancer and/or exonic splicing silencer affects factors for gene expression such as RNA structure. ${ }^{18-22}$ It is indicated that the SNP in the DPCR1 having exonic splicing enhancer/silencer sequence can affect the gene expression level.

\section{Conclusions}

In summary, we failed to find an association in both analyses, except for one SNP, rs2517449, and $\mathrm{FEV}_{1}$ decline, and the SNP is assumed to have a role in splicing efficiency. Although the present study reveals lack of association between DCPR1 polymorphisms and AERD, our findings may be meaningful for future studies validating the function of DPCR1 and/or researches regarding AERD or asthma.

\section{REFERENCES}

1. Matsuzaka Y, Tounai K, Denda A, Tomizawa M, Makino S, Okamoto $\mathrm{K}$, et al. Identification of novel candidate genes in the diffuse panbronchiolitis critical region of the class I human MHC. Immunogenetics 2002;54(5):301-309.
2. Fellay J, Ge D, Shianna KV, Colombo S, Ledergerber B, Cirulli ET, et al. Common genetic variation and the control of HIV-1 in humans. PLoS Genet 2009;5(12):e1000791.

3. Barcellos LF, May SL, Ramsay PP, Quach HL, Lane JA, Nititham J, et al. High-density SNP screening of the major histocompatibility complex in systemic lupus erythematosus demonstrates strong evidence for independent susceptibility regions. PLoS Genet 2009;5(10): e1000696.

4. Hijikata M, Matsushita I, Tanaka G, Tsuchiya T, Ito H, Tokunaga K, et al. Molecular cloning of two novel mucin-like genes in the diseasesusceptibility locus for diffuse panbronchiolitis. Hum Genet 2010; 129(2):117-128.

5. Kim HJ, Lee YH, Im SA, Kim K, Lee CK. Cyclooxygenase inhibitors, aspirin and ibuprofen, inhibit MHC-restricted antigen presentation in dendritic cells. Immune Netw 2010;10(3):92-98.

6. Bateman ED, Hurd SS, Barnes PJ, Bousquet J, Drazen JM, FitzGerald M, et al. Global strategy for asthma management and prevention: GINA executive summary. Eur Respir J 2008;31(1):143-178.

7. Crapo RO, Casaburi R, Coates AL, Enright PL, Hankinson JL, Irvin $\mathrm{CG}$, et al. Guidelines for methacholine and exercise challenge testing-1999. This official statement of the American Thoracic Society was adopted by the ATS Board of Directors, July 1999. Am J Respir Crit Care Med 2000;161(1):309-329.

8. American Thoracic Society. Standardization of spirometry, 1994 Update. Am J Respir Crit Care Med 1995;152(3):1107-1136.

9. Morris JF. Spirometry in the evaluation of pulmonary function. West J Med 1976;125(2):110-118.

10. Cormican LJ, Farooque S, Altmann DR, Lee TH. Improvements in an oral aspirin challenge protocol for the diagnosis of aspirin hypersensitivity. Clin Exp Allergy 2005;35(6):717-722.

11. Kim TH, Chang HS, Park SM, Nam BY, Park JS, Rhim T, et al. Association of angiotensin I-converting enzyme gene polymorphisms with aspirin intolerance in asthmatics. Clin Exp Allergy 2008;38(11): 1727-1737.

12. Hedrick PW. Gametic disequilibrium measures: proceed with caution. Genetics 1987;117(2):331-341

13. Stephens M, Smith NJ, Donnelly P. A new statistical method for haplotype reconstruction from population data. Am J Hum Genet 2001;68(4):978-989.

14. Azuma A, Kudoh S. Diffuse panbronchiolitis in East Asia. Respirology 2006;11(3):249-261.

15. Homma H, Yamanaka A, Tanimoto S, Tamura M, Chijimatsu Y, Kira S, et al. Diffuse panbronchiolitis. A disease of the transitional zone of the lung. Chest 1983;83(1):63-69.

16. Szczeklik A, Stevenson DD. Aspirin-induced asthma: advances in pathogenesis and management. J Allergy Clin Immunol 1999;104(1): 5-13.

17. Todate A, Chida K, Suda T, Imokawa S, Sato J, Ide K, et al. Increased numbers of dendritic cells in the bronchiolar tissues of diffuse panbronchiolitis. Am J Respir Crit Care Med 2000;162(1):148-153.

18. Blencowe BJ. Alternative splicing: new insights from global analyses. Cell 2006;126(1):37-47.

19. Fu XD. Towards a splicing code. Cell 2004;119(6):736-738.

20. Wang GS, Cooper TA. Splicing in disease: disruption of the splicing code and the decoding machinery. Nat Rev Genet 2007;8(10):749-761.

21. Xue Y, Zhou Y, Wu T, Zhu T, Ji X, Kwon YS, et al. Genome-wide analysis of PTB-RNA interactions reveals a strategy used by the general splicing repressor to modulate exon inclusion or skipping. Mol Cell 2009;36(6):996-1006.

22. Liu W, Zhou Y, Hu Z, Sun T, Denise A, Fu XD, et al. Regulation of splicing enhancer activities by RNA secondary structures. FEBS Lett 2010;584(21):4401-4407. 